\title{
Possible Mechanisms and Significance of the Neonatal Surge in Glucagon Secretion: Studies in Newborn Lambs
}

\author{
LUIZ A. GRAJWIR, MAPK A. SPIERIING, JOSEPH SACK, AND IDEIBERT A. FISHIER
}

Deparment of Pedicatrics, UCLA-Larbor General Hospital, Torrance, California, USA

Summary

Studies were conducted in newborn lambs to gain insight into the significance and mechanism(s) responsible for the rapid rise in plasma immunoreactive glucagon (IRG) which occurs in human and other newborn species immediately after delivery. Three sets of experiments were conducted: group $A$, control studies $(n=5)$ in which delivery into room air was followed $1 \mathrm{hr}$ later by cutting of the umbilical cord and periodic blood sampling for a further hour; group $B$, studies $(n=5)$ in which somatostatin (SRIF), a known inhibitor of IRG and insulin (IRI) secretion, was infused into the fetus for $10 \mathrm{~min}$ before, and for 1 hr after delivery and immediate cord cutting; group) $C$, studies ( $n$ $=5$ ) in which an identical dose regimen of SRIF was infused into fasting newborn lambs aged 24-72 hr. The doses of SRIF used were several fold higher than those proven to suppress pancreatic hormone secretion in other species.

In the control studies, plasma IRG levels remained stable until the cord was cut, after $w$ hich event levels rose 5 - 6 -fold (5) \pm 15 $\mathrm{pg} / \mathrm{ml}$ to $305 \pm 98 \mathrm{pg} / \mathrm{ml}, P<0.05)$. Simultaneously, plasma free fatty acid (FFA) concentrations rose significantly $(280 \pm 80$ to $780 \pm 100 \mu \mathrm{Eq} /$ liter, $P<0.05)$ and IRI remained unchanged. Plasma glucose concentrations, however, in contrast to observations in other species, did not fall, and therefore, hypoglycemia was not the stimulus for the glucagon surge.

SRIF infusion at birth (group B) did not prevent the rise in IRG. Again blood glucose values did not fall, but in contrast to the control studies plasma IRI levels rose and the rise in FFA did not occur. Later SRIF infusion (group $C$ ) resulted in a prompt and sustained suppression of IRG and IRI and a significant fall in blood glucose.

These results suggest that an adrenergic mechanism rather than curtailment of nutrients is the major stimulus to the neonatal surge in IRG.

\section{Speculation}

The surge in IRG following delivery is a widespread and possibly universal phenomenon in mammalian species. The surge appears to be activated by adrenergic stimuli rather than interruption of nutrient supply after scparation from the placenta. In addition to the IRG rise, these adrenergic stimuli inhibit IRI secretion, thereby favoring lipolysis, glycogenolysis, and ketogenesis. These (and possibly other) hormonal changes may be key adaptive events for energy homeostasis in the transition to extrauterine life.

A prompt and significant increase in plasma IRG concentration. maximal within hours of birth, occurs in human newborn infants $(2,24)$. Similar changes have been observed in newborn rats (15) and rabbits (1). Accompanying these rises in IRG is a concomitant fall in glucose concentration, and the changes in glucose and glucagon are negatively correlated $(15,24)$. Since glucagon acts to raise blood glucose, it wals proposed that the neonatal surge in IRG was an important adaptice event in the organism's transition from intrauterinclife, and that the stimulus to this surge was hypoglycemia or a falling blood glucose (15, 24). In order to test this hypothesis, and to further ascertain the significance of the observed hormonal changes after birth, we have conducted studies in newborn lambs. This species has been widely used to study perinatal metabolism $(4-6,8,9,11,13$, 16-18, 28). It was therefore important to know whether the neonatal surge in IRG also occurred in this species and, if so. whether it was related to a fall in blood glucose. In addition, could the neonatal surge in IRG be prevented or modified by SRIF, a known inhibitor of IRG secretion (29), and, if so, what were the metabolic sequelate?

\section{MATERIALS AND METHODS}

ANIMAL EXPIRIMENTS

Healthy date-bred pregnant ewes (Columbia-Suffolk cross) were studied close to term ( 145 days of gestation). In all experiments, a uterotomy was performed under local anesthesia and a catheter was implanted in the fetal femoral artery or jugular vein depending on whether the hindleg or fetal head was most conveniently exposed. After a re-equilibration period of 30 min. the fetuses were delivered and the following experiments were performed.

Group A: Control. Five lambs were delivered and the umbilical cord was left intact and covered with warm saline so that the blood supply to the fetus was not disturbed. The fetal face was covered with a warm saline-filled glove. Blood samples were taken at 15-min intervals during the first hour. One hour after delivery the umbilical cord was cut and the glove was removed immediately. Further blood samples were withdrawn 15, 30, and 6) min after the cord was cut.

Group B: SRIF-infused. In five lambs cyclic SRIF (a gift of Dr. Roger Guillemin) was infused into the fetus as a 5()$-\mu \mathrm{g}$ bolus followed by $200 \mu \mathrm{g} / \mathrm{hr}$ via a constant infusion pump. The SRIF was diluted in normal saline immediately before use. In these studies the bolus of SRIF. followed by constant infusion, was initiated 10 min before delivery and continued for 60 min after delivery and immediate cord cutting. Blood samples were withdrawn at 15 -min intervals commencing $15 \mathrm{~min}$ before delivery and for 2 hr after delivery. Delivery and cord cutting wero deemed to be zero time.

Group $C$ : SRIF Infusion in 2t-72-hr Lambs. It has been reported that SRIF does not inhibit basal plasma IRG and IRI in the adult sheep, in contrast to other species (3). Therefore, we attempted to determine whether SRIF was capable of inhibiting IRG and IRI in the newborn lamb. SRIF was infused into five newborn lambs aged 24-72 hr. Each lamb was fasted for 3-4 hr and infused with SRIF as a pulse of $50 \mu \mathrm{g}$ followed by 200$) \mu \mathrm{g}$ over 1 hr. Blood samples were withdrawn before infusion and at 5,30 , and 60 min after commencing infusion. 


\section{ANALYTIC TECHNIQUES}

Each blood sample of $2 \mathrm{ml}$ was placed in chilled tubes containing EDTA plus Trasylol $0.1 \mathrm{ml}(1,00)($ kallikrein inhibitory units). The plasma was promptly separated in a refrigerated centrifuge and stored frozen at $-20^{\circ}$ until assayed for glucagon, insulin, glucose, and FFA. Plasma IRG was determined by double antibody radioimmunoassay (RIA) highly discriminatory for pancreatic glucagon (25). IRI was determined by a modification of the double anitbody RIA or Norgan and Lazarow (20). Plasma glucose was determined by a glucose oxidase technique (31). FFA was measured using the extraction method of Dole (10).

Statistical analysis employed the paired and unpaired Student $t$-test.

\section{RESULTS}

Figure 1 illustrates the changes in IRG following delivery in group A. Before cord cutting plasma IRG was remarkably stable, ranging only from $58 \pm 19 \mathrm{pg} / \mathrm{ml}$ (mean \pm SEM) at zero time to $59 \pm 15 \mathrm{pg} / \mathrm{ml} 60 \mathrm{~min}$ postdelivery. After umbilicil cord cutting there was a rapid and significant rise in IRG to $304 \pm 98$ $\mathrm{pg} / \mathrm{ml}$ evident $15 \mathrm{~min}$ later. Mean values remained at levels of $163 \pm 74 \mathrm{pg} / \mathrm{ml}$ and $144 \pm 75 \mathrm{pg} / \mathrm{ml}$ at 90 and $120 \mathrm{~min}$, respectively, but these concentrations were not significantly different from values before cord cutting. The corresponding insulin, glucose and FFA data are shown in Figure 2. Plasma insulin fell from $20 \pm 6$ to $10 \pm 2 \mu \mathrm{U} / \mathrm{ml}$ at 60 min after delivery, but this change was not significant. After cord cutting, values remained essentially unchanged. Mean plasma glucose concentration rose from $18 \pm 1 \mathrm{mg} / 100 \mathrm{ml}$ at delivery to a peak of $34 \pm 8$ $\mathrm{mg} / \mathrm{l}(0) \mathrm{ml} 45 \mathrm{~min}$ after birth; this change also was not significant. After cord cutting there was no fall in mean plasma glucose concentration. Mean plasma FFA concentration remained unchanged until cord cutting, when values rose from $280 \pm 8()$ $\mu \mathrm{Eq} /$ liter at zero time to $780 \pm 100 \mu \mathrm{Eq} /$ liter at $30 \mathrm{~min}(P<$ (0.01). Mean FFA remained elevated throughout the subsecuent period of experimental observation.

The results of experiments in which SRIF infusion was begun in utero are depicted in Table 1 . It is clear that despite SRIF infusion glucagon rose significantly after cord cutting and reached a peak of $226 \pm 48 \mathrm{pg} / \mathrm{ml}(P<0.01)$ at $60 \mathrm{~min}$. Although this concentration appeared to be lower than the peak achieved without SRIF $(304 \pm 98 \mathrm{pg} / \mathrm{ml})$, the values are statistically similar. Cessation of SRIF infusion was followed by a further elevation of IRG to $362 \pm 121 \mathrm{pg} / \mathrm{ml}$. Mean plasma IRI remained unchanged until 60 min after birth, at which time it was significantly higher than the mean zero time concentration $(P<0.05)$. As in group $A$, plasma glucose did not fall signifi-

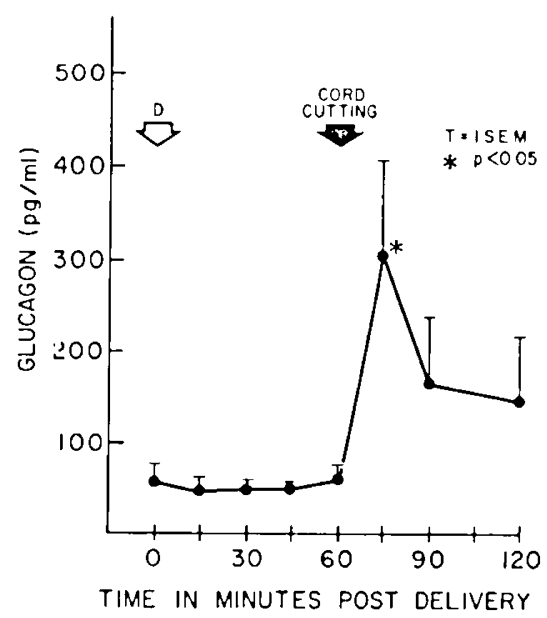

Fig. 1. Pattern of immunoreactive glucagon (picograms per ml) after delivery and umbilical cord cutting in the lamb. The abrupt rise after cord cutting is apparent.
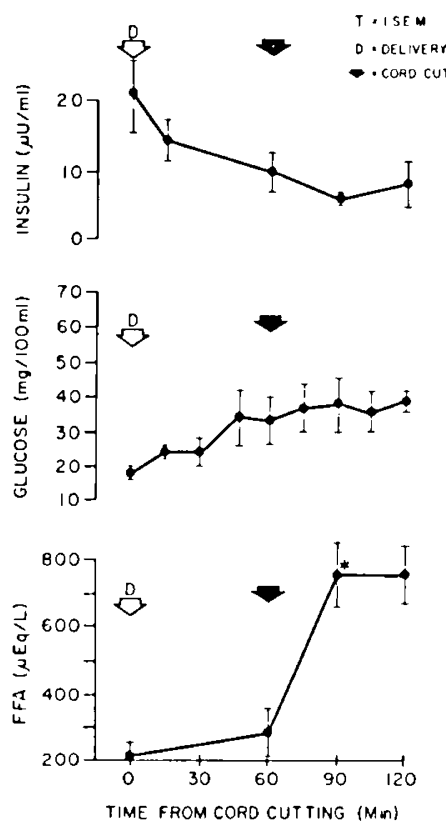

Fig. 2. Pattern of immunoreactive insulin, glucose, and free fatty acids (FFA) after delivery and umbilical cord cutting in newborn lambs. Samples are from the same animals as shown in Figure 1. Asterisk $\left(^{*}\right)$ represents a statistically significant change $(P<0 .(01)$. Note that glucose does not fall after separation from the placenta.

cantly. In contrast to the group A result, however, the rise in mean FFA concentration was not observed during SRIF infusion.

Table 2 summarizes the changes from basal in IRG, IRI, and glucose in two periods following infusion of SRIF to newborn lambs (group $C)$. The first period $(0-5 \mathrm{~min})$ represents the changes in response to the bolus injection, whereas the second period $(0-60$ min) shows the changes induced by constant infusion. IRG and IRI were rapidly suppressed $(P<0.01$ and $P<$ 0.05 . respectively) and remained suppressed throughout the infusion period. Plasma glucose also declined, the change at 60 min being significant $(P<0.05)$.

\section{DISCUSSION}

The present results demonstrate that the surge in IRG after delivery occurs in lambs as in other species, although others have not observed it (1). Failure to detect the IRG surge could have been due to the timing of collecting samples, since the surge occurs within 30 min after cutting the umbilical cord. In every species hitherto examined the postnatal surge in IRG has been identified. In the sheep, however, unlike the human $(2,24)$ or rat (15), the surge of IRG could not be related to a fall in blood gluocse; blood glucose concentrations remained essentially unchanged in the $2 \mathrm{hr}$ after delivery. Glucose is the major source of energy for the lamb fetus during the last trimester and for the newborn lamb; amino acids, acetate, and lactate also contribute significantly as energy substrate in this species (4-6,16). A fall in amino acids such as might occur after cutting the umbilical cord, is not known to be a stimulus to glucagon secretion; rather. elevated amino acid levels stimulate $\operatorname{IRG}$ release $(3,12,21)$. Thus, unless acetate and/or lactate are major nutrients for the lamb, and unless their curtailment following cord cutting triggers glucagon secretion, other mechanisms must be involved. We have not measured acetate or lactate in our experiments. and therefore cannot totally exclude this possibility. Other possibilities that must be considered as explanations for the surge include redistribution of IRG following loss of the placental pool. or adrenergic mechanisms known to be potent stimuli to IRG secretion (3)). 
Table 1. Change's during somatostatin (SRIF) infusion at birth'

\begin{tabular}{|c|c|c|c|c|c|c|c|}
\hline & \multicolumn{7}{|c|}{ Time (min) from delivery } \\
\hline & -15 & 0 & 5 & 15 & 30 & 60 & 75 \\
\hline \multicolumn{8}{|c|}{ Glucigon, $\mathrm{pg} / \mathrm{ml}$} \\
\hline Mcan & 29 & 34 & 145 & $167^{2}$ & $213^{2}$ & $2260^{2}$ & $362^{3}$ \\
\hline \pm SENI & 15 & 14 & 50 & 23 & 69 & 48 & 121 \\
\hline$n$ & 3 & 4 & 5 & 5 & 4 & 4 & 3 \\
\hline \multicolumn{8}{|c|}{ Insulin, $\mu \mathrm{U} / \mathrm{ml}$} \\
\hline Mean & 6 & 6.4 & 9.4 & 8.2 & 12.3 & $27^{3}$ & $31.5^{3}$ \\
\hline$\pm \mathrm{SEM}$ & 1.2 & 2.6 & 2.7 & 1.9 & 1.7 & 6.7 & 7.6 \\
\hline$n$ & 5 & 5 & 5 & 5 & 3 & 3 & 3 \\
\hline \multicolumn{8}{|c|}{ Gilucose, $\mathrm{mg} / \mathrm{l}(00) \mathrm{ml}$} \\
\hline Mean & 30 & 24 & 35 & 53 & $6(1)$ & 64 & 59 \\
\hline \pm SEMI & 8 & 7 & 6 & 11 & 14 & 19 & 25 \\
\hline$n$ & 5 & 4 & 5 & 5 & 4 & 4 & 3 \\
\hline \multicolumn{8}{|c|}{ Free fatty acids, $\mu E_{y} /$ liter } \\
\hline Mean & & 274 & 340 & 292 & 312 & 3.35 & \\
\hline \pm SEM1 & & 22 & 27 & 43 & 48 & 41 & \\
\hline$n:$ & & 4 & 4 & 4 & 4 & 4 & \\
\hline
\end{tabular}

'SRIF was given as a bolus of $50 \mu \mathrm{g}$ followed by $200 \mu \mathrm{g} / \mathrm{hr}$ commencing 10 min before delivery and immediate cord cutting (0) lime). SRIf infusion ceased at $60 \mathrm{~min}$.

$2 P<0.01$ compared to zero time.

$3 P<0.05$ compared to zero time.

Table 2. Change's during somatostatin (SRIF) infusion in newborn lambs'

\begin{tabular}{|c|c|c|}
\hline Time & $0-5 \mathrm{~min}$ & $0-60 \mathrm{~min}$ \\
\hline $\begin{array}{l}\text { Aclucagon, } \mathrm{pg} / \mathrm{ml} \\
\quad \pm \text { SEMI }\end{array}$ & $\begin{array}{r}-42.8 \\
10.5^{5}\end{array}$ & $\begin{array}{l}-54.2 \\
9.5^{2}\end{array}$ \\
\hline دInsulin, $\mu \mathrm{U} / \mathrm{ml}$ & -7.2 & -9.0 \\
\hline \pm SEM & $1.9^{: 1}$ & $3.3^{3}$ \\
\hline$\Delta$ Glucose, $\mathrm{mg} / \mathrm{dl}$ & -4.0 & -11.5 \\
\hline \pm SEM & 3.1 & $3.9^{3}$ \\
\hline
\end{tabular}

Since the placental fluid distribution space represents approximately one-half of the fetal blood volume, and since placental transfer of glucagon does not occur in either direction (26), the observed 5 -fold rise in glucagon after cord cutting must represent increased secretion. Simple redistribution would account for only a doubling of basal levels; that is, a rise to approximately $120 \mathrm{pg} / \mathrm{ml}$, rather than the observed $304 \mathrm{pg} / \mathrm{ml}$. It is conceivable that a system for degrading glucagon exists in the placenta and that removal of the distribution space plus the degradation site could account for the observed increases.

The possibility can be considered that adrenergic mechanisms activated by cord cutting at delivery stimulate the IRG surge. Fpinephrine and norepinephrine are known to be capable of stimulating glucagon release as well as inhibiting the release of insulin (30). Moreover, catecholamines are lipolytic hormones that mobilize FFA. Plasma insulin levels remained low and FFA did rise after umbilical cord cutting in the present studies. Thus. the observed changes could be accounted for on the basis of catecholamine secretion, and catecholamines have been implieated in the surge of other hormones such as triiodothyronine after umbilical cord cutting in the newborn sheep $(14,22)$. Consequently, catecholamine release, triggered by cord cutting, would seem a likely stimulus to the observed IRG surge. Delivery per se did not appear to trigger a significant surge in catecholamines inasmuch as before cord cutting in the control animals plasma glucagon and FFA concentrations remained stable.
It is of particular interest that SRIF did not entirely inhibit the neonatal IRG surge in the present study. We did show (Table 2) that SRIF is capable of suppressing IRG and IRI in the new born lamb, as it is in other species (29). Moreover, this suppression resulted in a fall in blood glucose, providing preliminary evidence for a significant role of glucigon in neonatal glucose homeostasis. More extensive studies concerning this aspect are reported elsewhere (27). Thus, failure of SRIl to entirely inhibit the immediate neonatal surge is not due to lack of effectiveness of SRIF in the newborn lamb. Rather, the stimulus to IRG release appears to override the suppressive effect of SRIF. although the possibility that some suppression occurred is suggested by the rebound rise in IRG subsequent to ceasing the infusion of SRIF at $60 \mathrm{~min}$. Again the possibility of a catecholatmine-mediated phenomenon arises. SRIF at doses known to suppress the secretion of other hormones does not suppress the release of catecholamines (7). It is conceivable, therefore, that the suppressive effects of SRIF were heing overcome. However, in order to explain the differences in the pattern of plasma IRI and plasma FFA levels during SRIF infusion, as compared to the pattern in the control series, it is necessary to postulate an interaction between SRIF and the $\alpha$-adrenergic receptor. Such interaction between SRIF and adrenergic mechanisms involved in pancreatic hormone secretion has recently been reported in dogs (23). The results of our experiments also suggest such an interaction in that a predominantly $\beta$-adrenergie stimulus would raise IRG and IRI secretion, the latter preventing the rise in FFA. FFA levels indeed failed to rise in our experimental animals after SRIF, whereas insulin levels increased significantly (Table 1).

In sum, we would propose that our experimental observations are best explained by a surge in catecholamines triggered by umbilical cord cutting. Under normal circumstances this catecholamine surge may initiate several hormonal changes $(14,22)$, including the surge in glucagon and maintenance of low insulin. The combined metabolic effects of these changes would augment FFA and glucose kevels, as well as hepatic ketogenesis (19), thereby maintaining neonatal energy homeostasis during the initial critical period after delivery. So potent is the stimulus for the neonatal surge in IRG that it cannot be overcome by SRIF at doses which clearly inhibit IRG secretion in lambs aged 1-3 days. 


\section{CONCLUSION}

Studies conducted in newborn lambs revealed that the abrupt rise in IRG which characteristically follow's separation from the placenta in other species also occurs in sheep. Since plasma FFA levels rose while plasma insulin concentrations remained low and plasma glucose did not change significantly, an adrenergic mechanism rather than curtailment of nutrients or simple hormone redistribution would seem to be a possible stimulus to the observed changes. Infusion of SRIF, a known inhibitor of pancreatic hormone secretion, did not prevent the immediate postnatal surge in IRG. However, SRIF infused into lambs aged 1-3 day's produced the expected suppression of IRG as well as IRI, and while both hormones were suppressed blood glucose levels fell. The results suggest that the observed surge in IRG after delivery is an important adaptive event for maintenance of energy homeostasis in the neonatal period.

\section{REFERENCES AND NOTES}

1. Assan, R., Attali, J. R., Ballerio, G., Girard, J. R., Hautecouverture, M. Kervran, A., Plouin. P. F., Slama, G.. Soufflet, E., Tchobroutsky, G., and Tiengo, A.: Some aspects of the physiology of glucagon. In: W'. J. Malaisse and J. Pirart: Diabetes, pp. 144-179 (Excerpta Nedica, Amsterdam 1974).

2. Bloom, S. R., and Johnston, D. I.: Failure of glucagon release in infants of diahetic mothers. Brit. Med. J., 4: 453 (1972).

3. Bryce, D., Yeh, M., Funderburk, C., Todd, H., and Hertelendy, F.: Studies on growth hormone secretion, VII. Effects of somatostatin on plasma G.H., insulin, and glucagon in sheep. Diabetes, 24: 842 (1975).

4. Burd, L. I., Jones, M. D., Simmons, M. A., Makowski, E. L., Meschia, G., Battaglia, F. C.: Placental production and foetal utilization of lactate and pyruvate. Nature, 254: 710 (1975)

5. Char, V. C., and Creasy, R. K.: Lactate and pyruvate as fetal metabolic substrates. Pediat. Res., 10: 231 (1976).

6. Char, V. C., and Creasy, R. K.: Acetate as a metabolic substrate in the fetal lamb. Amer. J. Physiol., 230: 357 (1976).

7. Christeneen, N. J., Christensen, S. E., Hansen, A. P., and Lundbaek, K.: The effect of somatostatin on plasma nor-adrenaline and plasma adrenaline concentrations during exercise and hypoglycemia. Metabolism, 24: 1267 (1975).

8. Crenhaw, C.: Fetal glucose metabolism. Clin. Obstet. Gynecol., 13: 579. (1970).

9. Curet, L.: Physiological aspects of amino acid transport across the placenta. Clin. Obstet. Gynecol.. 13: 586 (1970).

10. Dole. V. P.: A relation between nonesterfied fatty acids in plasma and the metabolism of glucose. J. Clin. Invest., 35: 150 (1956).

11. Fiser, R. H., Jr., Erenberg, A., Sperling, M. A., Oh, W., and Fisher, D. A. Insulin-glucagon-substrate interrelations in the fetal sheep. Pediat. Res., \&: $951(1974)$

12. Fiser, R. H., Phelps, D., Williams, P., Sperling, M. A., Oh, W., and Fisher. D. A.: Alanine stimulation of the pancreatic alpha and beta-cell in the neonatal lamb. Biol. Neonate 25: 171 (1974).

13. Fiser, R. H., Jr., Phelps, D. L., Williams, P. R., Sperling, M. A., Fisher, D. A., and $\mathrm{Oh}, \mathrm{W} .:$ Insulin-glucagon substrate interrelationships in the neor nagtal sheep. Amer. J. Obstet. Gynecol., 120: 944 (1974).

14. Fisher, D. A., and Sack. J.: Thyroid function in the neonate and possible approaches to new born screening for hypothyroidism. In: D. A. Fisher and G. N. Burrow: Perinatal Thyroid Physiology and Disease, Rp. 197-209 (Raven Press, New York, 1975).
15. Girard, J. R., Cuendet, G. S., Marliss, E. B., Kervran, A., Rieutort, M., and Assan, R.: Fuels, hormones, and liver metabolism at term and during the early postnatal period in the rat. J. Clin. Invest., 52: 3190 (1973).

16. Gresham, E. L., James, E. J., Raye, J. R., Battaglia, F. C., Makowski, E. L., and Meschia, G.: Production and excretion of urea by the fetal lamb. Pediatrics, 50: 372 (1972).

17. James E. J., Meschia, G., and Battaglia, F. C.: A-V differences of free fatty acids and glycerol in the ovine umbilical circulation. Proc. Soc. Exp. Biol. Med., 138: 823 (1971).

18. James, E. J., Raye, J. R., Gresham, E. L., Makowski, E. L. Meschia, G. and Battaglia, F. C.: Fetal oxygen consumption, carbon dioxide production, and glucose uptake in a chronic sheep preparation. Pediatrics, 50: 361 (1972).

19. McGarry, J. D., Wright, P. H., and Foster, D. W.: Hormonal control of ketogenesis. J. Clin. Invest., 55: 1202 (1975).

20. Morgan, C. A., and Lazarow, A.: Immunoassay of insulin: Two antibody system. Plasma insulin levels of normal, subdiabetic and diabetic rats. Diabetes, 12: 115 (1963)

21. Rocha, D. M., Faloona, F. R., and Unger. R. H.: Glucagon-stimulating activity of 20 amino acids in dogs. J. Clin. Invest., 5I: 2346 (1972).

22. Sack, J., Beaudry, M., Delamater, P. V., Oh, W., and Fisher, D. A.: Umbilical cord cutting triggers hypertriiodothyroninemia and non-shivering thermogenesis in the newhorn lamb. Pediat. Res., 10: 169 (1976).

23. Smith, P. H., Woods, S. C.. and Porte. D., Jr.: Phentolamine blocks the somatostatin-mediated inhibition of insulin secretion. Endocrinology, 98: $1073(1976)$.

24. Sperling, M. A., DeLamater, P. V., Phelps, D., Fiser, R. H., Oh, W., and Fisher, D. A.: Spontaneous and amino acid stimulated glucagon secretion in the immediate post-natal period: Relation to glucose and insulin. J. Clin. Invest., 53: 1159 (1974).

25. Sperling, M. A., DeLamater, P. V., Fiser, R. H., Fisher, D. A., and Kazenelson, M.: Development and application of a radioimmunoassay for glucagon. Clin. Chem., 20: 566 (1974)

26. Sperling, M. A., Erenberg, A., Fiser, R. H., Oh. W., and Fisher, D. A. Placental transfer of glucagon in sheep. Endocrinology, 93: 1435 (1973).

27. Sperling, M. A., Grajwer, L. A., Leake, R. D., and Fisher, D. A.: Metabolic effects of somatostatin in newborn lambs [Abstr.]. Pediat. Res., 10: 415 (1976).

28. Tsoulos, N. G., Colwill, J. R., Battaglia, F. C., Makowski, E. L., and Meschia, G. Comparison of glucose, fructose, and $\mathrm{O}_{2}$ uptakes by fetuses of fed and starved ewes. Amer. J. Physiol., 221: 234 (1972)

29. Vale, W Brazeau, P., Rivier, C., Brown, M., Boss, B.. Rivier, J., Burgus, R., Ling, N., and Guillemin, R.: Somatostatin. Recent Progr. Horm. Res., 31 : $365(1975)$

30. Woods, C., and Porte, D., Jr.: Neural control of the endocrine pancreas. Physiol. Rev., 54: 596 (1974).

31. Beckman glucose analyzer, Beckman Instruments, Fulterton, Calif.

32. The authors gratefully acknowledge the technical assistance of Ms. Sandra Voina and Mr. Donald Padgett, and the secretarial assistance of Ms. Joy Reynolds.

33. Dr. Sperling is a recipient of a Research Career Development Award from the United States Public Health Service (1 kO 4111$)(0029)$.

34. This research was supported in part by United States Public Health Service Grant HD 07087 and HD (04270 from the National Institute of Child Health and Human Development of National Institutes of Health, Bethesda, Maryland and by the Juvenile Diabetes Foundation.

35. Requests for reprints should be addressed to: M. A. Sperling. M.D., Pediatric Endocrinology, Harbor General Hospital, B-5, I000) W. Carson St.. Torrance. Calif. 90509 (USA)

36. Received for publication September 13,1976.

37. Accepted for publication November 23, 1976. 